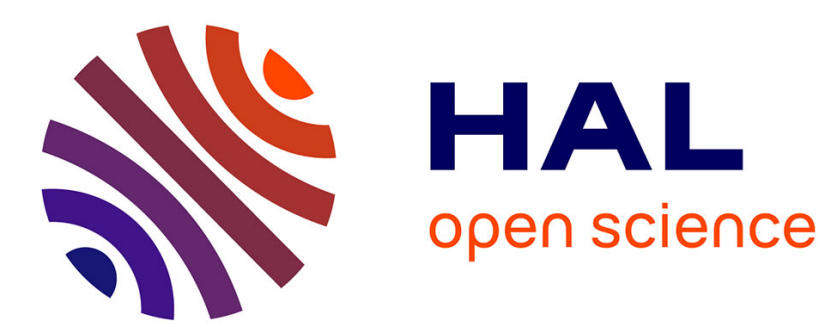

\title{
Fluorescent Phosphorus Dendrimers: Towards Material and Biological Applications
}

\author{
Jieru Qiu, Aurélien Hameau, Xiangyang Shi, Serge Mignani, Jean Pierre \\ Majoral, Anne-Marie Caminade
}

\section{- To cite this version:}

Jieru Qiu, Aurélien Hameau, Xiangyang Shi, Serge Mignani, Jean Pierre Majoral, et al.. Fluorescent Phosphorus Dendrimers: Towards Material and Biological Applications. ChemPlusChem, 2019, 84 (8), pp.1070-1080. 10.1002/cplu.201900337 . hal-02335059

\section{HAL Id: hal-02335059 \\ https://hal.science/hal-02335059}

Submitted on 2 Nov 2020

HAL is a multi-disciplinary open access archive for the deposit and dissemination of scientific research documents, whether they are published or not. The documents may come from teaching and research institutions in France or abroad, or from public or private research centers.
L'archive ouverte pluridisciplinaire HAL, est destinée au dépôt et à la diffusion de documents scientifiques de niveau recherche, publiés ou non, émanant des établissements d'enseignement et de recherche français ou étrangers, des laboratoires publics ou privés. 


\section{Fluorescent Phosphorus}

Dendrimers: Towards Material and Biological Applications

Jieru Qiu, ${ }^{[a, b, c]}$ Aurélien Hameau, ${ }^{[a, b]}$ Xiangyang

Shi, ${ }^{[c]}$ Serge Mignani, ${ }^{[d, e]}$ Jean-Pierre Majoral ${ }^{[a, b]}$ and Anne-Marie Caminade ${ }^{\star[a, b]}$

\section{Properties of fluorescent phosphorus dendrimers}

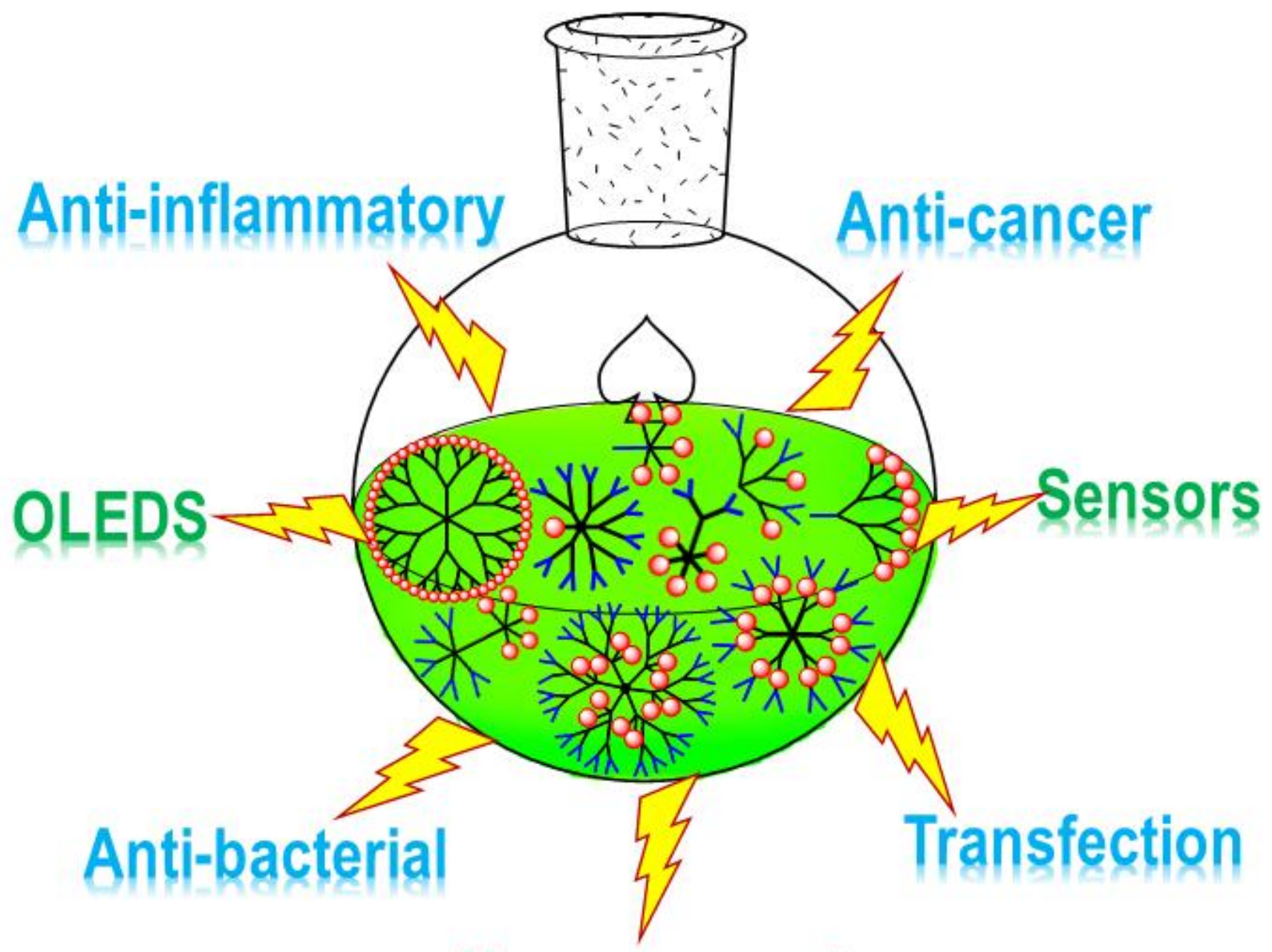

Nanocomposites 
Abstract: Fluorescent derivatives of phosphorhydrazone dendrimers are reviewed. Diverse types of fluorophores have been used such as pyrene, naphthol, anthracene, dansyl, diketone, phthalocyanine, maleimide, julolidine, rhodamine, fluorescein or fluorene derivatives. The fluorescent groups can be located as terminal groups on the surface, or at the core, or linked to the core (off-center) or to the branches of the dendritic structure. After fundamental researches, these compounds have been used in the fields of catalysis, nanomaterials, OLEDs, sensors and biology/nanomedicine, in particular for monitoring transfection, anti-inflammatory, or anti-cancer properties.

\section{Introduction}

Dendrimers are hyper-branched macromolecules, ${ }^{[1]}$ constituted by the association of monomers, as for polymers, but synthesized step-by-step, and not by polymerization reactions. This step-by-step synthesis enables a perfect control over the molecular 3-dimensional structure, shape, size, number and type of terminal functions, and a batch-to-batch high reproducibility. Each time the number of terminal functions is increased during the step-by-step process, a new generation is obtained. Dendrimers attract a considerable attention since more than 30 years,${ }^{[2]}$ in particular for their large variety of properties in very different fields. Among them, fluorescent dendrimers ${ }^{[3]}$ offer particular features of interest for chemistry, but also for physics/nanomaterials, ${ }^{[4]}$ and for biology/nanomedicine. ${ }^{[5]}$

Most types of dendrimers are organic, constituted of $\mathrm{C}, \mathrm{H}, \mathrm{N}, \mathrm{O}$, with generally a nitrogen atom at the branching points. ${ }^{[6]}$ However, other types of dendrimers exist, in particular those having main group elements as branching points, in particular phosphorus and silicon. ${ }^{[7]}$ Phosphorus-containing dendrimers ${ }^{[8]}$ have also a large number of properties, in particular for

[a] J. Quu, Dr. A. Hameau, Dr. J.P. Majoral, Dr. A.M. Caminade Laboratoire de Chimie de Coordination (LCC) CNRS

205 route de Narbonne, BP 44099, 31077 Toulouse Cedex 4, France

E-mail: anne-marie.caminade@lcc-toulouse.fr

[b] J. Qiu, Dr. A. Hameau, Dr. J.P. Majoral, Dr. A.M. Caminade LCC-CNRS

Université de Toulouse, CNRS

Toulouse, France

[c] J. Qiu, Prof. X. Shi

Key Laboratory of Science \& Technology of Eco-Textile

Ministry of Education, College of Chemistry, Chemical Engineering and Biotechnology, Donghua University

Shanghai 201620, China

[d] Dr. S. Mlgnani

CNRS-UMR 860, Laboratoire de Chimie et de Biochimie Pharmacologique et de Toxicologie

Université Paris Descartes, PRES Sorbonne-Paris Cité

45 rue des Saints Pères, 75006 Paris, France

[e] Dr. S. Mlgnani

CQM Centro de Quimica da Madeira, MMRG

Universidade da Madeira

Campus de Pentrada, 9020-105 Funchal, Portugal. nanomaterials ${ }^{[9]}$ and for nanomedicine, ${ }^{[10]}$ depending mostly on

Anne-Marie Caminade is Director of Research, Exceptional Class at the CNRS in Toulouse, and the head of the "Dendrimers and Heterochemistry" team. Her current research interest is on dendrimers, in particular phosphorus dendrimers and on their applications. She is co-author of about 472 publications, 55 book chapters, 30 patents, and editor of 2 books (h index 67 , over 14,275 citations).

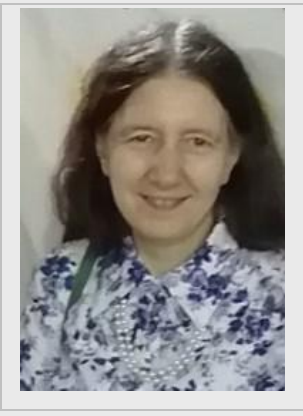

the type of their terminal functions, easily modified starting from the "native" terminal functions which are either aldehydes or $\mathrm{P}(\mathrm{S}) \mathrm{Cl}_{2}$ groups. This review will display the properties of fluorescent phosphorus dendrimers, for the elaboration of smart nanomaterials, and mainly for biology/nanomedicine. It will be organized according to the type of fluorophore, whatever its localization in the dendritic structure. For each type of fluorophore, the properties will be discussed after the synthesis. All the dendritic chemical structures will be drawn in a linear form, with parentheses at each branching point, but a drawing of the shape will be given in all cases.

\section{Fluorescent phosphorhydrazone dendrimers and their properties}

The very first example of fluorophores linked to phosphorhydrazone dendrimers and dendrons were pyrene derivatives, but their fluorescence properties have not always been recorded.

\subsection{Pyrene derivatives}

Pyrene derivatives have generally a high fluorescence quantum yield, and also the possibility to form excimers by association of two pyrenes, detectable by large modifications of the fluorescence wavelength. ${ }^{[11]}$ In the first example of phosphorus dendritic compounds, a hydrazide pyrene derivative has been linked to the surface of dendrons (dendritic wedges), by condensation with the aldehyde terminal functions. The presence of a triethoxysilyl group at the core of the dendron (Figure 1a) enabled the co-hydrolysis and polycondensation with tetraethoxysilane (TEOS), via a sol-gel protocol, to afford functionalized hybrid silica. ${ }^{[12]}$ The fluorescence properties were not recorded.

Amino pyrene was grafted to the surface of phosphorhydrazone dendrimers of generations 1 to $4\left(G_{1}\right.$ to $\left.G_{4}\right)$, by condensation with the aldehydes (Figure $1 \mathrm{~b}$ ). ${ }^{[13]}$ The hydrazide pyrene and the amino pyrene have been included also inside the structure of dendrimers, during the synthetic process (Figure 1c). In these cases, the reaction occurred with the $\mathrm{P}(\mathrm{X}) \mathrm{Cl}_{2}$ terminal functions ( $\mathrm{X}=\mathrm{O}$ or $\mathrm{S}$ ), but selectively on a single $\mathrm{Cl}$ and not on both $\mathrm{Cl}$. This interesting possibility has been illustrated in several cases, particularly when using primary or secondary amines. ${ }^{[14]}$ The 
remaining $\mathrm{Cl}$ was then used for continuing the growing of the dendrimer up to $G_{2}$, but the fluorescence was not recorded. ${ }^{[15]}$

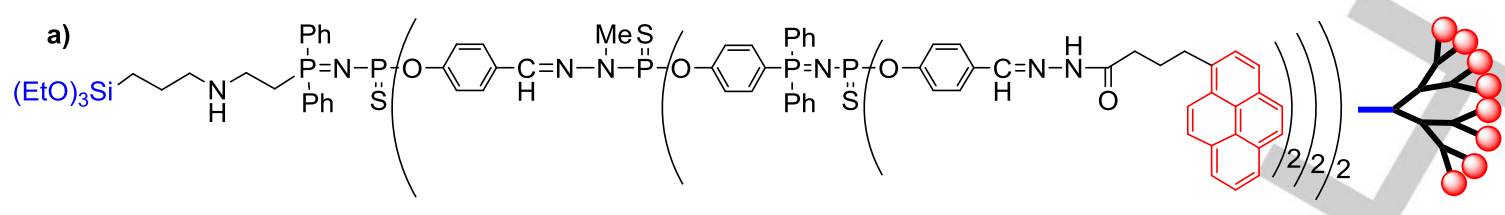

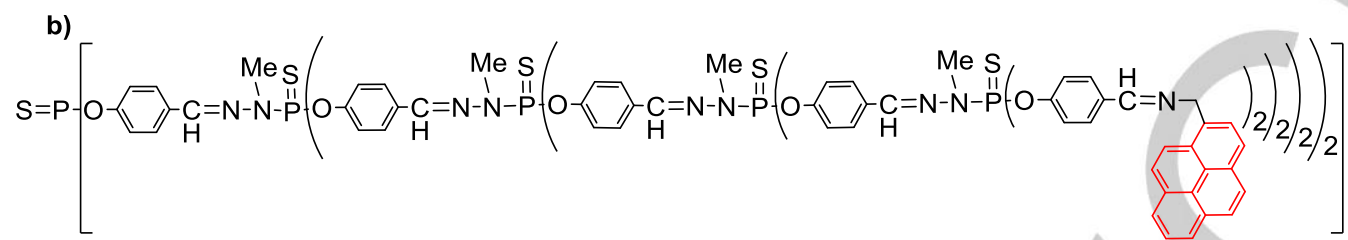

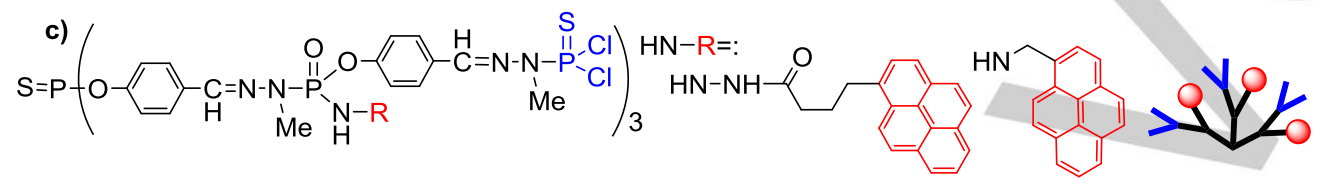

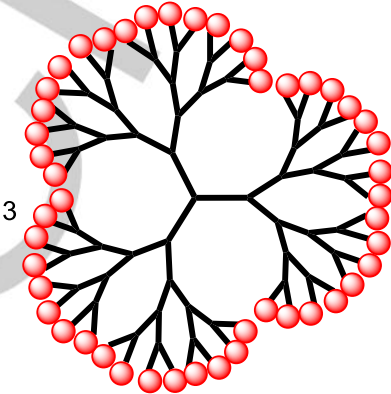

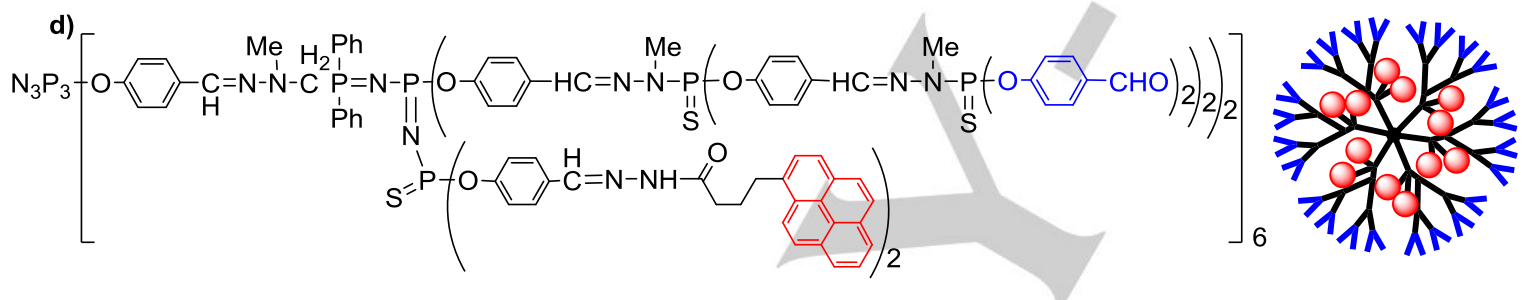

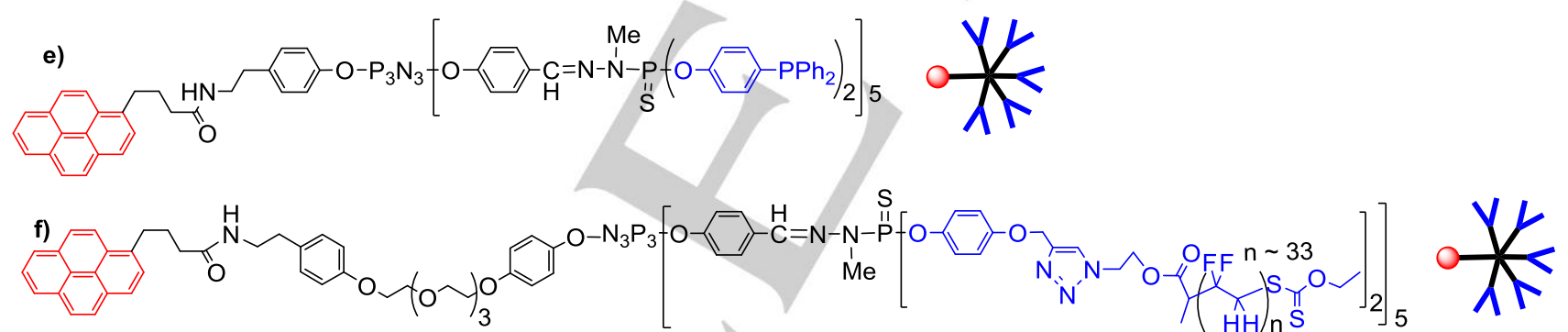

Figure 1. Diverse dendritic compounds incorporating pyrene derivatives in their structure; a) on the surface of $G_{3}$ dendrons; b) on the surface of $G_{4}$ dendrimers, used in OLEDs; c) and d) inside the structure of dendrimers; e) and f) linked to the core of $\mathrm{G}_{1}$ dendrons, for interacting with graphene-coated cobalt nanoparticles.

Pyrene hydrazido derivatives have been grafted inside the structure of a dendrimer, after its synthesis, thanks to the presence of $\mathrm{P}=\mathrm{N}-\mathrm{P}=\mathrm{S}$ linkages. Indeed, such linkage can be modified in three steps, i.e. alkylation on sulfur with alkyl triflates, which induces a weakening of the P-S bond, easily cleaved by a nucleophilic phosphine such as $\mathrm{P}\left(\mathrm{NMe}_{2}\right)_{3}$ in the second step. This reaction affords $\mathrm{P}=\mathrm{N}-\mathrm{P}$ : linkages, incorporating a free phosphine, able to react with functionalized azides in Staudinger reactions, creating in particular $\mathrm{P}=\mathrm{N}-\mathrm{P}=\mathrm{N}-\mathrm{P}=\mathrm{S}$ linkages, and allowing many different reactions inside very original structures. ${ }^{[16]}$ Twelve hydrazido pyrene have been grafted in this way inside the structure of a third generation dendrimer (Figure 1d). Steady-state fluorescence spectra and decays of excitations studies indicated the presence of many solvent molecules in the interior of dendrimers, and that movements of internally located pyrenes were not reduced by interactions with the interior of dendrimer. The ratio of the intensities of pyrene-pyrene excimer and pyrene monomer emissions decreased when the solvent viscosity increased, which disfavors the formation of the excimer, for both the dendrimer and a small model compound bearing two pyrenes. ${ }^{[17]}$

Two different types of dendrons having a single pyrene derivative linked to the core were synthesized, with the aim of interacting them through $\pi-\pi$ stacking with magnetic cobalt nanoparticles covered by a few graphene layers. In both cases, the dendrons were obtained by the differentiation of one function among six on the cyclotriphosphazene core $\left(\mathrm{N}_{3} \mathrm{P}_{3} \mathrm{Cl}_{6}\right){ }^{[18]}$ The first example concerned dendrons of generations zero and one, having either 5 or 10 derivatives of triphenyl phosphine on the surface, suitable for the complexation of palladium (Figure 1e). 
The loading of the dendrons onto the nanoparticles (NP) decreased as the size of the ligand increased, and loadings of 0.1 and $0.03 \mathrm{mmol}$ of pyrene tags per gram of NP were measured for $G_{0}$, and $G_{1}$, respectively. Important desorption of the phosphine dendrimers from the NPs surface was observed when heating the suspension to $60^{\circ} \mathrm{C} .^{[19]}$

In order to increase the loading of the dendrons on the Co NPs, a longer chain has been added between the pyrene and the $\mathrm{N}_{3} \mathrm{P}_{3}$ core, in particular 4 ethylene glycol groups. The surface of the dendron was functionalized with 10 poly(vinylidene fluoride) chains, using Huisgen's [3+2] cycloaddition reaction (Figure 1f). Fluorescence spectroscopy was used to monitor the decrease of the quantity of dendron in solution, when interacting with the graphene-coated Co NPs; only the pyrene monomer was detected. As previously, the interaction by $\pi-\pi$ stacking is reversible when heating. These tunable nanocomposites are the first example of coating of magnetic NPs with polymers through m-stacking interactions. ${ }^{[20]}$

\subsection{Pyrene derivatives for OLEDs, and nanomaterials for catalyst recycling}

The photoluminescence properties of the dendrimers shown in Figure $1 \mathrm{~b}$ were measured on thin films. After excitation at 250 $\mathrm{nm}$, a single very large emission band in the blue at $484 \mathrm{~nm}$ was observed in all cases, corresponding to the emission of excimers of pyrene. These dendrimers were used for making Organic Light Emitting Diodes (OLEDs), as the emissive layer, when mixed with PVK (poly(vinylcarbazole)). Nice blue electroluminescence was observed, but the intensity of the emission of light was low, only $3.5 \mathrm{~cd} / \mathrm{m}^{2}$. ${ }^{[13]}$

The dendrons complexing palladium and loaded on Cobalt NPs covered by graphene (Figure 1e) were used as catalysts for couplings of $\mathrm{ArBr}$ and $\mathrm{PhB}(\mathrm{OH})_{2}$ (Suzuki couplings). The reaction was carried out at $60^{\circ} \mathrm{C}$, enabling the catalysis to occur in the liquid phase in homogeneous conditions. Interestingly, this reaction was carried out to produce felbinac (an antiinflammatory drug) with a high efficiency (100\%). The catalytic system could be recovered, simply by cooling to room temperature for loading again the dendrons on the nanoparticles, and by using a magnet to recover the magnetic Co NPs. Recycling and reuse were carried out for 12 catalytic runs, with the same efficiency at each run, for the synthesis of felbinac. ${ }^{[19]}$

\subsection{Diverse aromatic hydrocarbon derivatives}

The grafting of a large number of functions on the surface of dendrimers is often carried out with the aim of inducing a synergy, due to their close proximity. This effect, in which a property is enhanced when the generation increases is called the dendritic (or dendrimer) effect. ${ }^{[21]}$ It can be extremely powerful when it is positive, but it can be also deleterious when it is negative. In the case of fluorescence, a close proximity of the fluorophores can induce quenching, through a non-radiative decay.

The grafting of naphthol on the surface of the second generation dendrimer was carried out directly on the $\mathrm{P}(\mathrm{S}) \mathrm{Cl}_{2}$ terminal functions (Figure 2a), but this dendrimer was not fluorescent. Anthracene was then tentatively grafted to the same dendrimer using the sodium salt of anthracen-9-ol, but the reaction could not be achieved. An alternative way of synthesis was found, using 9-anthraldehyde (Figure 2b). However, this dendrimer also was not fluorescent. ${ }^{[13]}$ In view of both failures, which might be due to the nature of the internal structure of the dendrimers, a dendrimer with a different internal structure was synthesized, based on $\mathrm{P}=\mathrm{N}-\mathrm{P}=\mathrm{S}$ linkages at all generations, ${ }^{[22]}$ then naphthol was grafted in the last step (Figure 2c). However, this dendrimer also was not fluorescent. ${ }^{[13]}$

$\beta$-diketones, obtained by reaction of 4 -hydroxyacetophenone with methyl pivalate have been grafted on the surface of dendrimers, from generations 1 to 4 (Figure 2d). The copper complexes of the diketones were tested as efficient catalysts in O-arylations of 3,5-dimethylphenol by aryl bromides. ${ }^{[23]}$ On the other side, the photoluminescence properties of difluoroboron derivatives of $\beta$-diketones are well-known, ${ }^{[24]}$ thus the $\beta$-diketone dendrimers have been reacted with $\mathrm{BF}_{3}$. However, the fluorescence is almost quenched in all cases (quantum yield ca $1 \%$ ); only the corresponding monomer is fluorescent (quantum yield $23 \%){ }^{[25]}$

Rhodamine derivatives are often used as sensitive labels for biological experiments, due to a $\mathrm{pH}$-driven ring-opening / ringclosure of a spirolactam ring, with the open form being colored and highly fluorescent, and the ring-closed form being colorless and non-fluorescent. ${ }^{[26]}$ The ring-closed form of a rhodamine derivative, functionalized by a phenol was grafted to the $\mathrm{P}(\mathrm{S}) \mathrm{Cl}_{2}$ terminal groups of a first generation dendrimer (Figure 2e). Attempts to open the spirolactam ring by adding $\mathrm{HCl}$ failed, and only protonation of the $\mathrm{NEt}_{2}$ substituent of rhodamine was obtained, thus no fluorescence was observed with this dendrimer. ${ }^{[27]}$

A small dendron, constituted of five dansyl groups and one tyramine linked to a cyclotriphosphazene was synthesized (Figure 2f), and the fluorescence properties were studied in different conditions. A notable decrease of the fluorescence quantum yield $(\Phi)$ of this dendron was observed, upon going from pure dioxane $(\Phi=51)$ to pure water $(\Phi=17)$. The fluorescence spectra of this compound in mixtures of various ratios of both solvents were recorded, and displayed a surprising behavior. Even a small quantity of water in dioxane (molar fraction 0.1) was sufficient to induce a large decrease in the fluorescence intensity. Furthermore, increasing the quantity of water induced an increased red-shift of the fluorescence wavelength from 492 to $524 \mathrm{~nm}$, up to a molar fraction of 0.8 in water. Then a dramatic blue-shift was observed as the quantity of water was increased up to pure water $(501 \mathrm{~nm})$. A good correlation was observed with the variation of the viscosity of the mixtures dioxane/water, which is maximal at 0.8 (molar fraction). ${ }^{[28]}$

This dendron was used to synthesize "Janus" dendrimers, $\left.{ }^{[29}\right]$ i.e. dendrimers having two different types of terminal functions, located in two different areas of the surface. A peptide-type coupling was used with a small dendron having one carboxylic acid at the core and five boc-protected amines, which were deprotected after the coupling, to afford a water-soluble and 
fluorescent $(\Phi$ in dioxane $=46 \%$ ) Janus dendrimer (Figure $2 \mathrm{~g}){ }^{[30]}$ A related Janus dendrimer was obtained by coupling a small dendron having one aldehyde with a first generation dendron having an hydrazide at the core (Figure $2 \mathrm{~h}$ ). The Janus dendrimer was also soluble in water, but its fluorescence was recorded in dioxane $(\Phi=30 \%) .{ }^{[30]}$

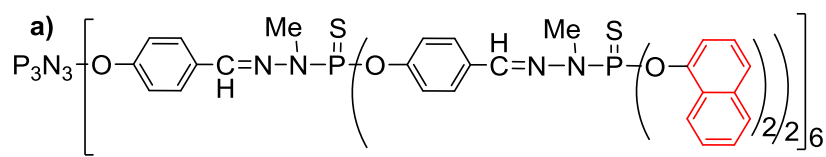

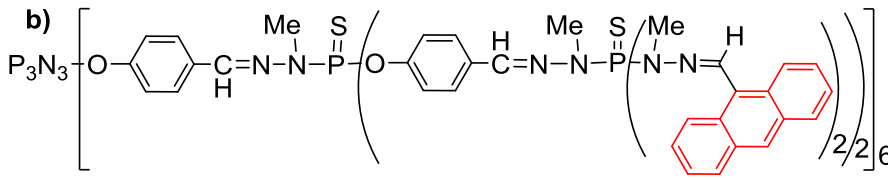

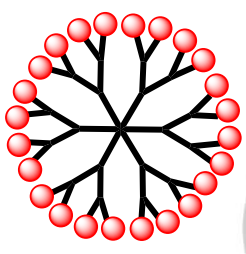

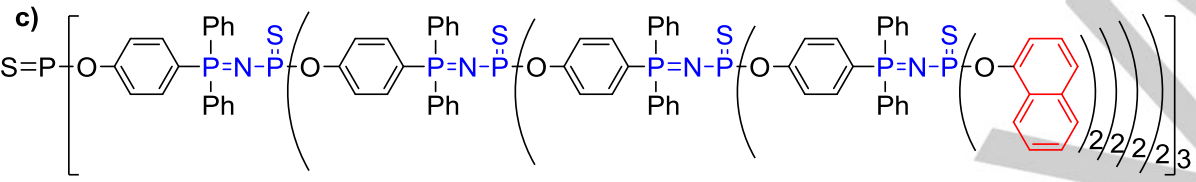

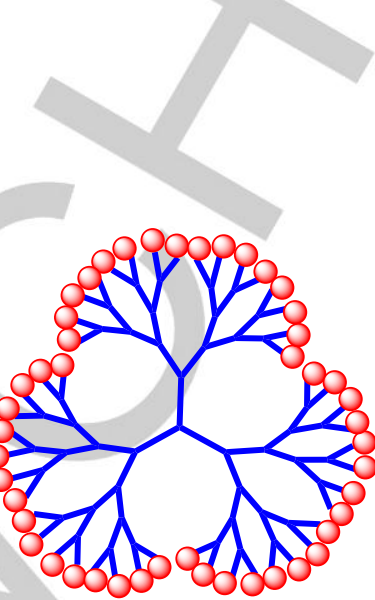

d)<smiles>CCNc1ccc2c(c1)Oc1cc(NCC)ccc1C21c2ccccc2C(=O)N1Cc1ccc(OP(C)(=S)NN(C)N=Cc2ccc(OS(C)(=O)=O)cc2)cc1</smiles>

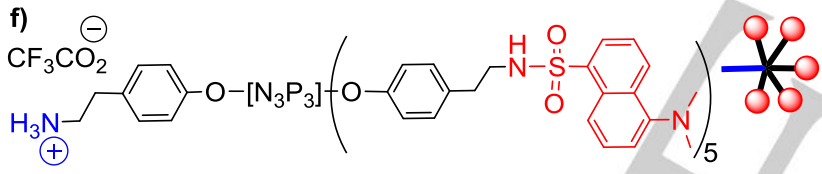<smiles>CCOc1ccc(CCNS(=O)(=O)c2cccc3c(N(C)CC)cccc23)cc1</smiles>

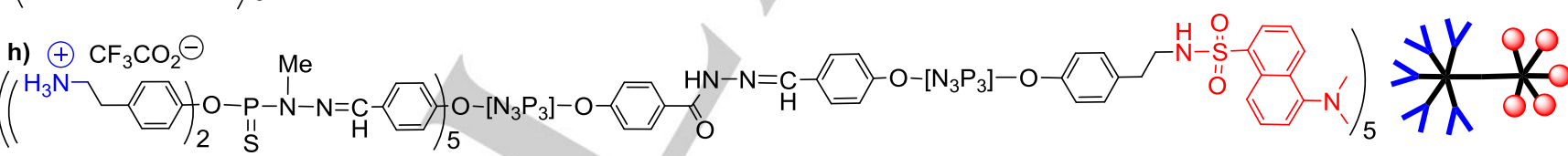

Figure 2. Diverse dendritic compounds incorporating potentially fluorescent aromatic hydrocarbon derivatives in their structure; a) to e) on the surface of the dendrimers; $f$ ) on the surface of a dendron; $g$ and $h$ ) on part of the surface of "Janus" dendrimers.

\subsection{Phthalocyanine as core of dendrimers}

Phthalocyanines are robust macrocycles with high chemical, thermal and light stability, but low solubility and variable fluorescence intensity. ${ }^{[31]}$ An octasubstituted phthalocyanine was synthesized and used as core of dendrimers, from generations 0 to 5 (Figure 3). UV-visible spectra show both a hyperchromic and bathochromic effect on the phthalocyanine Q-bands with increasing generations, indicating that the chromophore is more isolated, and that the dendritic shell mimics a highly polar solvent like DMF. The fluorescence properties of this family of dendrimers was studied in THF. The fluorescence quantum yield for the neutral form increased with increasing generation, from 0.33 for $G_{0}$ to 0.43 for $G_{3}$ and $G_{4}$ (aldehyde terminal functions in all cases). The dianionic form of the phthalocyanine core was poorly fluorescent, but an increase in the quantum yield was still observed, from 0.03 for $G_{0}$ to 0.07 and 0.11 for $G_{3}$ and $G_{4}$, respectively. The relatively high values obtained with the dendrimers show that each phthalocyanine is isolated from the others by the dendritic shell, which inhibits the quenching due to self-assembly. The fluorescence lifetimes were measured for the 
neutral species and were found to be about $5 \mathrm{~ns}$ for all compounds, whatever the generation of the dendrimers ( 0 to 4). ${ }^{[32]}$ Phthalocyanine copper complexes (generation 1) and cobalt complexes (up to generation 8) of these dendrimers have been obtained, but no fluorescence has been observed. ${ }^{[33]}$

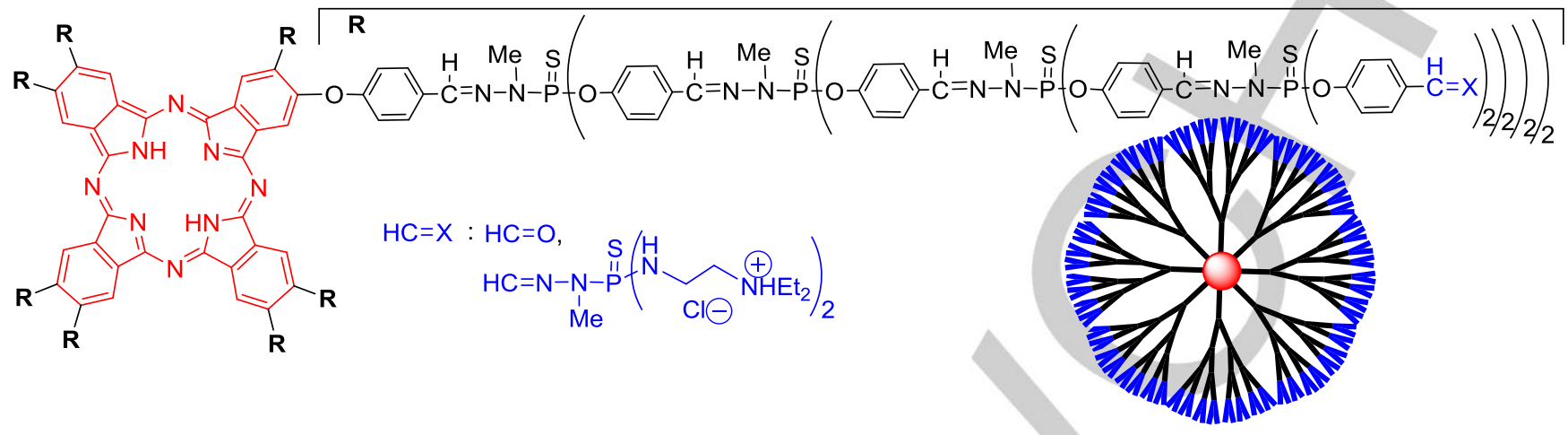

Figure 3. Phthalocyanine as core of dendrimers with different terminal functions (used as transfection agent with ammonium terminal functions).

Ammonium groups were grafted on the surface of a phthalocyanine-cored $\mathrm{G}_{5}$ dendrimer. This dendrimer was soluble in water, but it displayed a very special behaviour in this solvent. First, the UV-visible spectra of this compound in solution was very broad, and characteristic of a phthalocyanine in the solid state. Second, in ${ }^{1} \mathrm{H}$ NMR spectra, only signals corresponding to the external ethyl ammonium groups could be detected. Thus only the external hydrophilic shell was solvated, while the hydrophobic interior was un-solvated, and therefore rigid and anisotropic. Third, high-field NMR experiments using the pulsedfield gradient spin-echo NMR technique were carried out, in particular DOSY experiments (Diffusion ordered spectroscopy). A very small diameter of ca $6 \mathrm{~nm}$ was measured by this method, showing that the dendrimer is highly contracted. ${ }^{[34]}$ Indeed, the size measured for another $G_{5}$ phosphorhydrazone dendrimer was $9 \pm 0.5 \mathrm{~nm}^{[35]}$ Adding progressively THF to the watersolution of the phthalocyanine dendrimer induced, after an induction period, both the progressive re-appearance of the signals of the internal structure by ${ }^{1} \mathrm{H} N M R$, and the increase of the diameter of the dendrimer by DOSY NMR, up to ca $8.2 \mathrm{~nm}$. Furthermore, it was shown that lipophilic compounds could be entrapped in this dendrimer, and that it was able to modify the viscosity of the water/THF media. ${ }^{[34]}$

\subsection{Phthalocyanine derivatives for transfection}

The water-soluble and fluorescent dendrimer shown in Figure 3 was also used in biological experiments. It showed rather moderate cytotoxicity toward HeLa (Human epithelioid cervical carcinoma) and HEK 293 (Human transformed primary embryonal kidney) cell lines, and HUVEC (Human umbilical vein endothelial) cells in standard MTT assays in serum-containing medium. This compound was able to penetrate inside cells, and was efficiently used in transfection experiments, i.e. as carrier of negatively charged biological entities. It delivered fluoresceinlabeled oligodeoxyribonucleotide into HeLa cells. It was also able to deliver a DNA plasmid containing the functional gene of enhanced green fluorescent protein (EGFP), but failed to do so in HUVEC cell cultures. ${ }^{[36]}$

\subsection{Maleimide derivatives}

3,4-diaryl-substituted maleimide compounds are fluorophores which exhibit a large variation of emission spectra, depending on the substituents, and which have found uses in biology as labels, but also in OLEDs, as emitter. ${ }^{[37]}$ 3,4-diphenyl maleimide functionalized by a phenol has been grafted to the surface of dendrimers, from generation 0 to generation 3 (Figure 4a), but also linked to the core of dendrons (off-center), from generation 0 to generation 2 (Figure 4b). Both families of compounds are fluorescent, but the smallest compounds have the highest quantum yield of fluorescence. Indeed, $\Phi$ in THF varied from 78 to 39 for the $G_{0}$ and $G_{3}$ dendrimers, respectively, and from 77 to 20 for the $G_{0}$ and $G_{2}$ dendrons with aldehyde terminal functions, respectively. These data demonstrate that the deleterious influence of the branches upon the fluorophore close to the core is more important in the case of the dendrons. ${ }^{[38]}$

\subsection{Maleimide derivatives as transfection, anti-inflammatory, and sensor agents}

The dendron functionalized with ammonium terminal functions (Figure 4b) was soluble in water, and was tentatively proposed for biological experiments. Deceptively, the fluorescence of this dendrimer was very low in water. Toxicity assays have shown that this dendron was less cytotoxic towards HeLa cells than towards A549 cells (human lung cancer) and surprisingly, less toxic after 48 hours than after 24 hours. The interaction of the dendron with DNA was carried out with the plasmid DNA coding the gene of the fluorescent fusion protein BACE-GFP, by using circular dichroism (CD) spectroscopy. CD spectral changes observed were indicative of a possible partial disturbing of the Btype helical structure of DNA. Electrophoresis experiments confirmed the interaction, and thus the formation of a "dendriplex" 
(a complex of dendrimers with DNA, RNA, plasmid, etc.). Such behaviour indicates that this dendrimer is potentially interesting for transfection experiments. However, its low fluorescence intensity indicated that it is not suitable to monitor the cascade of biological events associated with transfection. ${ }^{[39]}$
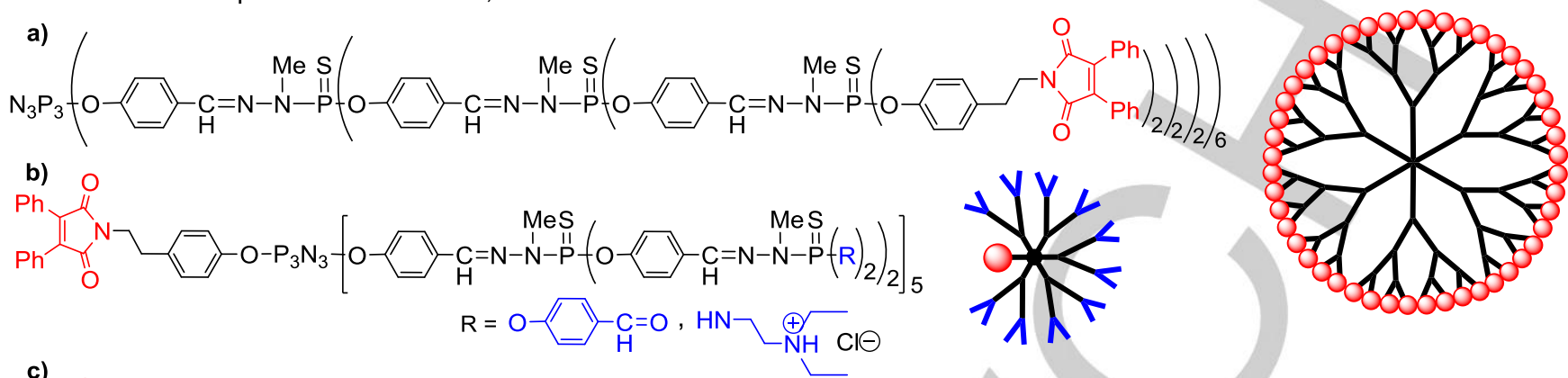
d) c)<smiles>COP(=O)(OC)C(O)c1ccc(OP(C)(=S)N(C)N=Cc2ccc(ONS(C)(O)(=S)Oc3ccc(CCN4C(=O)C(c5ccccc5)=C(C5CCCCC5)C4=O)cc3)cc2)cc1</smiles>

Figure 4. Dendrimers functionalized with maleimide fluorophores; a) on the surface; b) and c) linked to the core of dendrons; d) a small Janus dendrimer.

Another dendron bearing one maleimide linked to the core and equipped with azabisphosphonate terminal functions (Figure 4c) was synthesized as a fluorescent tool to monitor biological events, in particular the interaction with human monocytes. Fluorescence/Förster resonance energy transfer (FRET) experiments with antibodies coupled to phycoerythrin were carried out. These experiments indicated that the innate Toll-like receptor (TLR)-2 was involved, but not alone, in the sensing of the dendron/dendrimer by the monocytes. ${ }^{[40]}$

In the large structure/activity relationship study ${ }^{[41]}$ that was carried out after the discovery of the anti-inflammatory activation of monocytes by dendrimers functionalized with azabisphosphonate terminal functions, as potential treatment against rheumatoid arthritis ${ }^{[42]}$ and multiple sclerosis, ${ }^{[43]}$ a multiplication of the natural killer (NK) cells was also discovered. ${ }^{[4]}$ Human NK cells play a key role in anti-cancer and anti-viral immunity, and have a great potential for immunotherapeutic treatments against malignant diseases. However, NK cells are difficult to multiply, and the family of azabisphosphonate dendrimers offers such opportunity, with cultures of peripheral blood mononuclear cells (PBMCs) from healthy volunteers, or from cancer patients suffering from multiple myeloma. The fluorescent dendron shown in Figure 4c allowed to demonstrate that the first step for the multiplication of the NK population is the preliminary activation of monocytes, followed by a multistep cross-talk between monocytes and NK cells, before their proliferation. ${ }^{[45]}$

Besides the diverse biological properties explored with the maleimide dendrimers/dendrons, a maleimide Janus dendrimer (Figure 4d) was used as an optical sensor for hazardous phenol compounds. This dendrimer has two phosphonate groups on one side for the grafting to a nanocrystalline mesoporous titania thin film, and five maleimide fluorescent groups on the other side, for the sensing of phenols. The phenolic $\mathrm{OH}$ moieties (especially those of resorcinol and 2-nitroresorcinol), induced the quenching of the fluorescence of the maleimide groups. This quenching is more efficiently in the solid state (linked to the film) than in solution. ${ }^{[46]}$

\subsection{Julolidine derivatives for monitoring anti-inflammatory properties}

Julolidine derivatives are sensitive to the polarity and viscosity of their environment, and have been used as fluorescent labels for the detection of biomolecular interactions. ${ }^{[47]}$ In the case of phosphorhydrazone dendrimers and dendrons, julolidine derivatives have been synthesized only for biological purposes. Three first generation dendrons having one julolidine linked to the core and ten water-solubilizing functions have been synthesized (Figure 5a). The dendron with azabisphosphonate terminal groups was the first one synthesized. ${ }^{[48]}$ It was used first to perform equilibrium binding assays, which showed that it specifically interacted with purified $\mathrm{CD}^{+} \mathrm{T}$ cells, and inhibited their proliferation. ${ }^{[49]}$ It was shown also to be as active as the fully substituted dendrimer for the control of inflammatory diseases in different mouse models. ${ }^{[50]}$ The julolidine dendron bearing azabiscarboxylate $(A B C)$ terminal functions was synthesized for comparison with the azabisphosphonate (ABP) dendron. It was shown that the $A B C$ dendron interacted nonspecifically with the membrane of human monocytes and was 
not internalized, whereas the ABP dendron was readily internalized. These data indicated that the ABP dendrimer was recognized by specific receptor(s) located on the surface of human monocytes. ${ }^{[51]}$ The grafting of a single carboxylate on each terminal functions of the julolidine dendron was also carried for comparison with the ABP dendron. It appeared that the carboxylate dendron was non-active but toxic towards monocytes. ${ }^{[52]}$

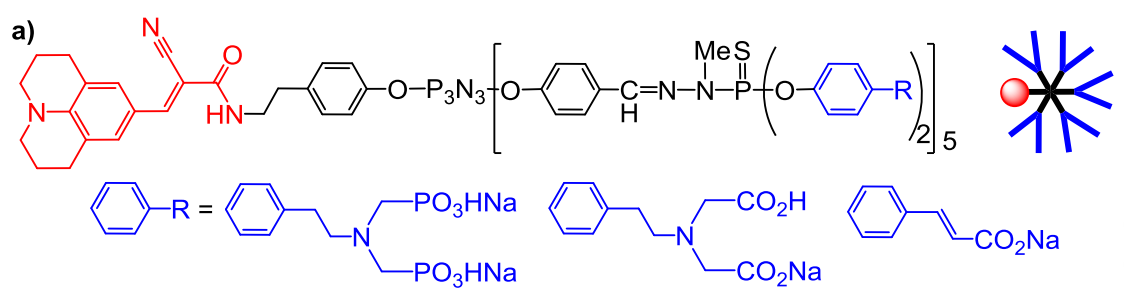

b)<smiles>CCOc1ccc(C=NNP(C)(=S)N(C)P(C)(=S)Oc2ccc(C=C=NNP(C)(=S)OP(=O)(Oc3ccc(CC)cc3)Oc3ccc(CC)cc3)cc2)cc1</smiles>

c)

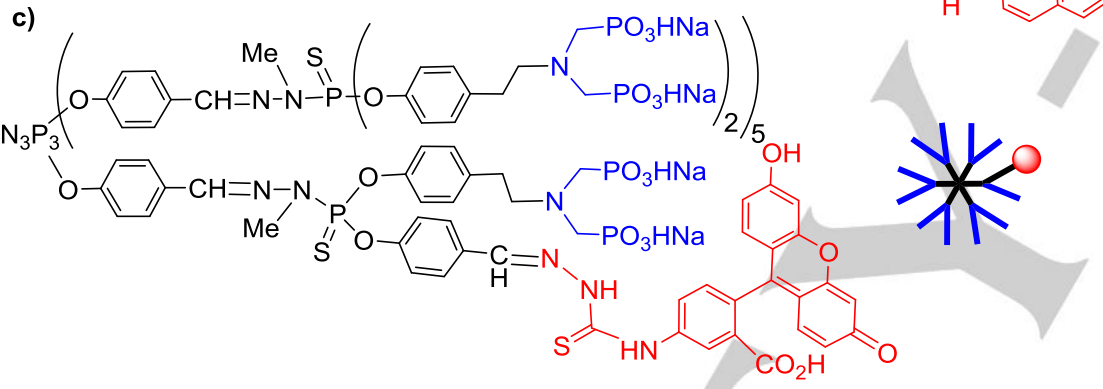
HOH $\mathrm{OH} 1.8$ $\mathrm{OH}^{2}$

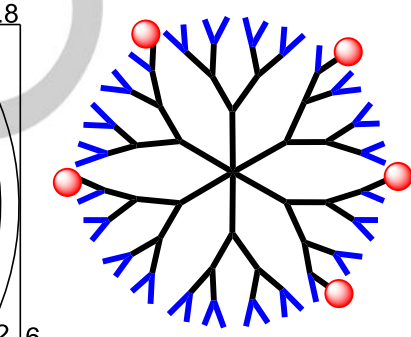

Figure 5. a) Julolidine linked to the core of a dendron bearing different water-solubilizing terminal functions; b) stochastic functionalization of a carbohydrate dendrimer by julolidine; c) stochastic functionalization of an azabisphosphonate dendrimer by fluoresceine.

A few julolidine derivatives were grafted on the surface of a generation 3 dendrimer, functionalized with trimannoside derivatives (Figure $5 \mathrm{~b}$ ). It is a stochastic functionalization, it means that approximately 5 julolidine were linked to each dendrimer, but their location was undefined, and some dendrimers had also 3 , or 4 , or 6 or 7 julolidine groups. In the same family of carbohydrate dendrimers, diverse compounds bearing 1 to 3 mannosides on each terminal group, and from generation 1 to 4 were synthesized, with the aim of mimicking the micelle-like supramolecular structure of mannose-capped lipoarabinomannan, which inhibits the production of proinflammatory cytokines in cells infected by Mycobacterium tuberculosis. This strategy occurs via binding to the C-type lectin DC-specific intercellular adhesion molecule 3 (ICAM-3)-grabbing non-integrin (DC-SIGN). Thus, a first screening of the dendrimers consisted in studying their binding interaction with DC-SIGN. $A G_{3}$ dendrimer bearing 48 trimannoside terminal functions and $\mathrm{a}_{4} \mathrm{G}_{4}$ dendrimer bearing 96 dimannosides displayed the highest binding avidity for DC-SIGN. The fluorescent $\mathrm{G}_{3}$ derivative (Figure $5 \mathrm{~b}$ ) was used for other analyses, in particular flow cytometry analyses, which revealed that this dendrimer directly interacted with mDC-SIGN on HEK cells. The anti-inflammatory activity of $\mathrm{G}_{3}$ dendrimer bearing 48 trimannoside caps was tested in vivo, in a model of acute lung inflammation. Mice received per os administration of the mannodendrimer, then were exposed to aerosolized LPS (lipopolysaccharide). Lung inflammation was significantly reduced in treated mice, compared to untreated. ${ }^{[53]}$

Another example of stochastic functionalization on the surface of dendrimers concerned the grafting of approximately one fluoresceine derivative on each first generation dendrimer ended by azabisphosphonate groups (Figure $5 \mathrm{c}$ ). This compound has anti-inflammatory properties, and it was used to study the early stages of the interaction of this family of dendrimers with monocytes. ${ }^{[40]}$

\subsection{Derivatives of fluorene as constituents of the branches, as transfection and anti-cancer agents}

Grafting a fluorophore to the surface or to the core of dendrimers necessitates to have only one active function. Using a fluorophore as branches of a dendrimer necessitates to have two different functions on the fluorophore, both being compatible with the classical synthetic process of synthesis of the dendrimer. In the case of phosphorhydrazone dendrimers, the easiest way is to use the fluorophore to replace hydroxybenzaldehyde, thus 
the fluorophore should be functionalized on one side by a phenol, and on the other side by a benzaldehyde. Only few fluorophores of this type were synthesized, one example is shown in Figure 6. All the compounds having a fluorophore as constituent of the branches were synthesized to decipher biological processes, and thus have been functionalized on the surface with functions that have been shown previously to induce biological properties.
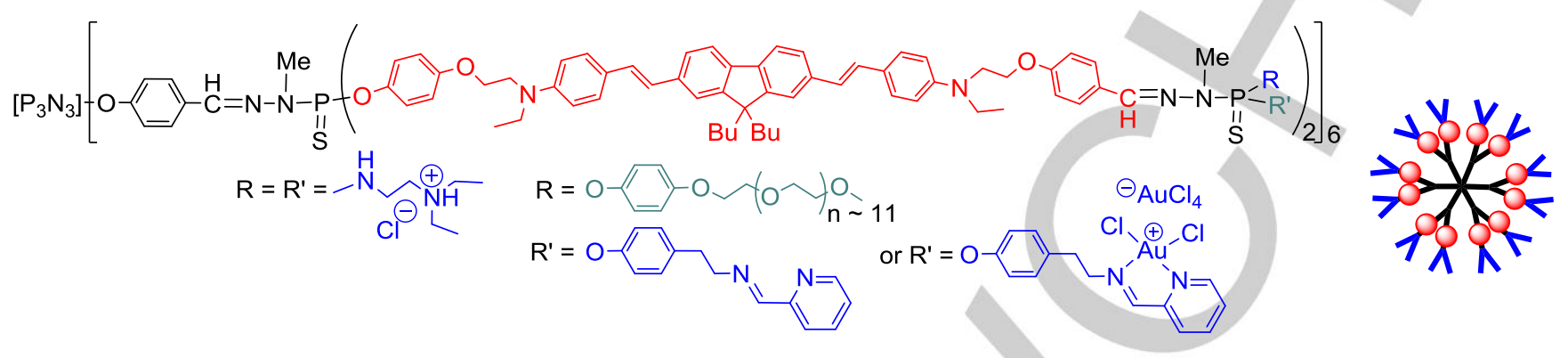

Figure 6. A derivative of fluorene as branches of second generation dendrimers bearing different types of terminal functions.

In a first example, the fluorescent dendrimer was functionalized on the surface by ammonium groups, which are known to be efficient for transfection experiments, ${ }^{[54]}$ and also for the penetration alone inside cells. ${ }^{[36]}$ The fluorescent dendrimer ended by ammonium groups (Figure 6 ) was readily internalized and retained by bone marrow-derived macrophages, showing its potential as cytoplasmic tracer. It can also be used for modelling and predicting drug and RNA/DNA delivery and distribution inside the cells. It was used also as a marker for monitoring cell behaviour and function in spinal cord injury, as it can assist in identifying the presence of macrophages and their phenotype status. ${ }^{[55]}$

Dendrimers having pyridine-imine functions and their copper complexes as terminal groups have been shown to possess anti-cancer properties towards a range of diverse types of cancerous cells. ${ }^{[56]}$ In order to decipher their mode of action, a fluorescent analogue of these dendrimers was synthesized, bearing both pyridine-imine and PEG (polyethyleneglycol) terminal functions to increase the solubility in water, which was decreased by the presence of the fluorophore (Figure 6). The fluorescent dendrimer avidly bonded to the cell membrane, even after cell washes, to remain predominantly concentrated outside the cell on the plasma membrane after a $4 \mathrm{~h}$ period. However, after $24 \mathrm{~h}$, it has entered the intracellular space in a much higher proportion. The complexation of the dendrimer with $\mathrm{Cu}$ (II) increased the cellular lethality and shifted the cell death to an original pathway, a caspase-independent process. It promoted the translocation of Bax (a pro-apoptotic protein) to the mitochondria and the release of AIF (Apoptosis Inducing Factor) and caspase 12 (protein). ${ }^{[57]}$

The same fluorescent dendrimer was complexed by gold, as shown in Figure 6. Compared to the copper complexes, a strong increase in the anti-proliferative activities against both HL-60 and $\mathrm{KB}$ tumoral cell lines were obtained, showing $\mathrm{IC}_{50}$ in the low nanomolar range. No synergy was observed between copper and gold concerning the anti-proliferative activities, but was indeed observed on the antimicrobial activity. The fluorescent dendrimer complexing gold on the surface was synthesized also to monitor the mechanism of action. ${ }^{[58]}$ These fluorescent dendrimers have been used as classical fluorophores, but they possess also two-photon absorption (TPA) properties, which are out of the scope of this review, as they necessitate more sophisticated methods, in particular a laser, to induce the excitation of the fluorophores. Several other dendrimers have been synthesized with the aim of possessing TPA properties, ${ }^{[59]}$ and used for instance for in vivo imaging, ${ }^{[60]}$ or for both imaging and photodynamic therapy. ${ }^{[61]}$

\section{Conclusion}

We have shown in this review the versatility of the location of fluorescent entities in the structure of phosphorhydrazone dendrimers, which is summarized in Figure 7. The location of the fluorophores is related to the type and number of functional group(s) they possess. Fluorophores possessing a single function can be grafted to the surface of dendrimers, either on the full surface, or in some places (stochastically), also on the surface of dendrons, on part of the surface of Janus dendrimers, to the core of dendrons, and to the branches inside the structure. Fluorophores possessing several identical functions can be used as core of dendrimers. Fluorophores possessing two different functions can be used as branches of dendrimers.

These various fluorescent dendritic structures are useful for a large panel of potential applications. On can cite in particular the creation of a sensitive chemical sensor for phenols, of blue emitting OLEDs, or of tunable nanocomposites in the field of nanomaterials. However, most properties of fluorescent phosphorhydrazone dendrimers concern their use in biology/nanomedicine, in particular to decipher their mechanisms of action in cells. This has been done in particular concerning dendrimers used as transfection agents, and for dendrimers having anti-inflammatory, anti-cancer, or antibacterial properties. In view of all the results already obtained, undoubtedly the use of fluorescent dendrimers for biology holds great promises for the future. 


\section{Acknowledgements}

Thanks are due to the CRC (Chinese Research Council) for a grant to one of us (JQ), to the PRC NSFC-CNRS 2019, and to the ANR 2017 SLOW2.

Keywords: biology $\bullet$ dendrimers $\bullet$ fluorescence $\bullet$ nanostructures - synthesis design
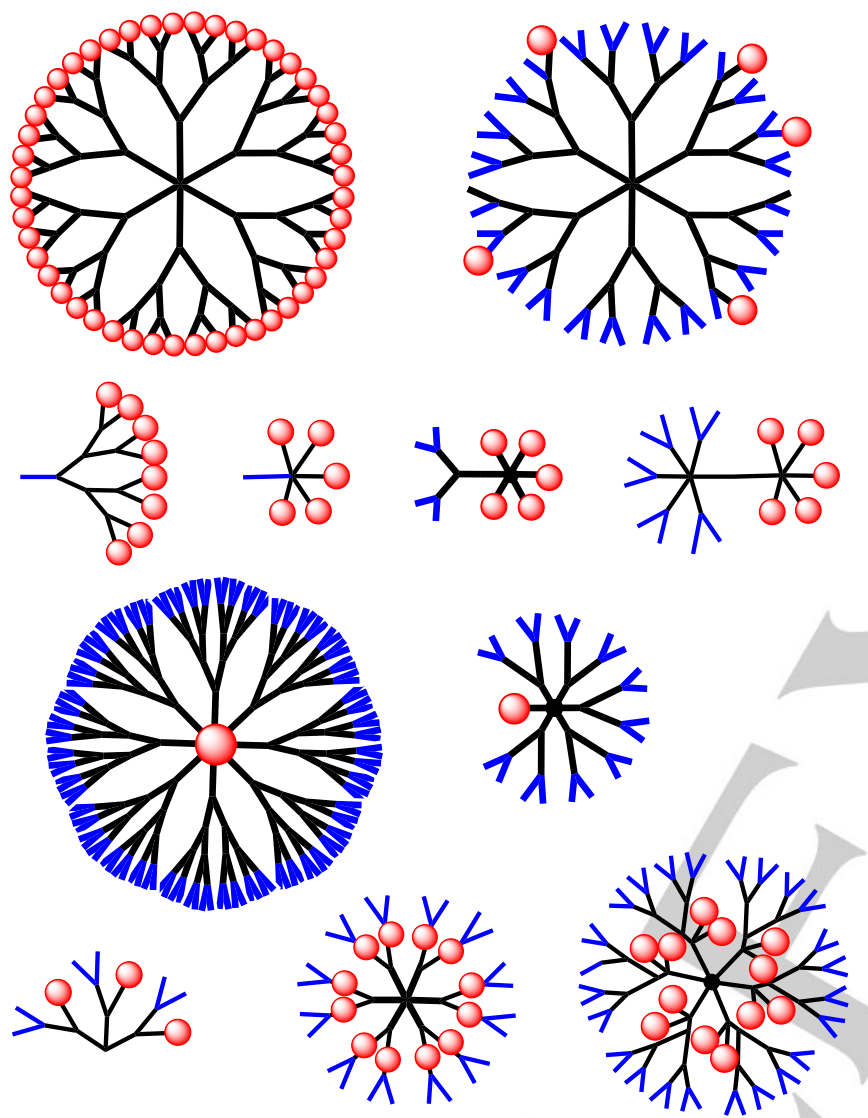

Figure 7. Different locations of fluorophores in phosphorhydrazone dendritic structures already synthesized.

[1] In Dendrimers: Towards Catalytic, Material and Biomedical Uses (Eds.: A. M. Caminade, C. O. Turrin, R. Laurent, A. Ouali, B. Delavaux-Nicot) John Wiley \& Sons Ltd., Chichester, UK, 2011.

[2] a) D. A. Tomalia, H. Baker, J. Dewald, M. Hall, G. Kallos, S. Martin, J. Roeck, J. Ryder, P. Smith, Polymer J. 1985, 17, 117-132; In Dendrimers, Dendrons, and Dendritic Polymers: Discovery, Applications, and the Future (Eds.: D. A. Tomalia, J. B. Christensen, U. Boas), Cambridge University Press, 2012.

[3] A. M. Caminade, A. Hameau, J. P. Majoral, Chem.-Eur. J. 2009, 15, $9270-9285$.

[4] a) P. L. Burn, S. C. Lo, I. D. W. Samuel, Adv. Mater. 2007, 19, 1675 1688; S. H. Hwang, C. N. Moorefield, G. R. Newkome, Chem. Soc. Rev. 2008, 37, 2543-2557.

[5] a) Z. Qiao, X. Y. Shi, Prog. Polym. Sci. 2015, 44, 1-27; b) A. M. Caminade, C. O. Turrin, J. Mater. Chem. B 2014, 2, 4055-4066; c) P. Trzepinski, B. Klajnert-Maculewicz, J. Chem. Technol. Biotechnol. 2017, 92, 1157-1166; d) S. Mignani, J. Rodrigues, H. Tomas, A. M. Caminade, R. Laurent, X. Y. Shi, J. P. Majoral, Science China-Mater. 2018, 61,
1367-1386; e) S. Mignani, J. Rodrigues, H. Tomas, M. Zablocka, X. Shi, A.-M. Caminade, J.-P. Majoral, Chem. Soc. Rev. 2018, 47, 514-532.

[6] a) In Dendrimers and Dendrons: Concepts, Syntheses, Applications (Eds.: G. R. Newkome, C. N. Moorefield, F. Vögtle), Wiley-VCH, 2001 b) In Dendrimers and Other Dendritic Polymers (Eds.: J. M. J. Fréchet, D. A. Tomalia), Wiley Series in Polymer Science, 2002; c) In Designing Dendrimers (Eds.: S. Campagna, P. Ceroni, F. Puntoriero), Wiley, 2011.

[7] a) J. P. Majoral, A. M. Caminade, Chem. Rev. 1999, 99, 845-880; b) A. M. Caminade, Chem. Soc. Rev. 2016, 45, 5174-5186.

[8] a) J.-P. Majoral, A.-M. Caminade, Eur. J. Inorg. Chem. 2019, 14571475; b) A. M. Caminade, J. P. Majoral, Molecules (Basel, Switzerland) 2018, 23; c) J. P. Majoral, A. M. Caminade, V. Maraval, Chem. Commun. 2002, 2929-2942; d) N. Launay, A. M. Caminade, R. Lahana, J. P. Majoral, Angew. Chem. 1994, 106, 1682-1684; Angew. Chem.-Int. Edit. Engl. 1994, 33, 1589-1592.

[9] a) A. M. Caminade, J. P. Majoral, Acc. Chem. Res. 2004, 37, 341-348; b) A. M. Caminade, A. Ouali, R. Laurent, C. O. Turrin, J. P. Majoral, Coord. Chem. Rev. 2016, 308, 478-497.

[10] a) A. M. Caminade, C. O. Turrin, J. P. Majoral, New J. Chem. 2010, 34, 1512-1524; A.-M. Caminade, Chem. Commun. 2017, 53, 9830-9838; c) In Phosphorus Dendrimers in Biology and Nanomedicine (Eds. A. M. Caminade, C. O. Turrin, J. P. Majoral), Pan Stanford Publishing, Singapore, 2018.

[11] T. Förster, K. Kasper, Z. Phys. Chemie 1954, 1, 275-277.

[12] C. O. Turrin, V. Maraval, A. M. Caminade, J. P. Majoral, A. Mehdi, C. Reye, Chem. Mater. 2000, 12, 3848-3856.

[13] L. Brauge, G. Veriot, G. Franc, R. Deloncle, A. M. Caminade, J. P. Majoral, Tetrahedron 2006, 62, 11891-11899.

[14] a) M. L. Lartigue, M. Slany, A. M. Caminade, J. P. Majoral, Chem.-Eur J. 1996, 2, 1417-1426; b) D. Riegert, A. Pla-Quintana, S. Fuchs, R Laurent, C. O. Turrin, C. Duhayon, J. P. Majoral, A. Chaumonnot, A. M. Caminade, Eur. J. Org. Chem. 2013, 2013, 5414-5422.

[15] M. Severac, J. Leclaire, P. Sutra, A. M. Caminade, J. P. Majoral, Tetrahedron Lett. 2004, 45, 3019-3022.

[16] a) C. Galliot, C. Larre, A. M. Caminade, J. P. Majoral, Science 1997 277, 1981-1984; b) C. Larre, A. M. Caminade, J. P. Majoral, Angew. Chem.-Int. Edit. Engl. 1997, 36, 596-599; c) C. Larre, D. Bressolles, C. Turrin, B. Donnadieu, A. M. Caminade, J. P. Majoral, J. Am. Chem. Soc. 1998, 120, 13070-13082; d) C. Larre, B. Donnadieu, A. M. Caminade, J. P. Majoral, J. Am. Chem. Soc. 1998, 120, 4029-4030.

[17] L. Brauge, A. M. Caminade, J. P. Majoral, S. Slomkowski, M. Wolszczak, Macromolecules 2001, 34, 5599-5606.

[18] a) A. M. Caminade, A. Hameau, J. P. Majoral, Dalton Trans. 2016, 45, 1810-1822; b) A.-M. Caminade, A. Ouali, A. Hameau, R. Laurent, C Rebout, B. Delavaux-Nicot, C.-O. Turrin, K. M. Chane-Ching, J.-P. Majoral, Pure Appl. Chem. 2016, 88, 919-929; c) L. Wang, Y.-X. Yang, X. Shi, S. Mignani, A.-M. Caminade, J.-P. Majoral, J. Mater. Chem. B 2018, 6, 884-895.

[19] M. Keller, V. Colliere, O. Reiser, A. M. Caminade, J. P. Majoral, A Ouali, Angew. Chem. Int. Ed. 2013, 52, 3626-3629.

[20] E. Folgado, M. Guerre, N. Mimouni, V. Colliere, C. Bijani, K. M. C Ching, A. M. Caminade, V. Ladmiral, B. Ameduri, A. Ouali, ChemPlusChem 2019, 84, 78-84.

[21] a) A. M. Caminade, A. Ouali, R. Laurent, C. O. Turrin, J. P. Majoral, Chem. Soc. Rev. 2015, 44, 3890-3899; b) B. Helms, J. M. J. Frechet, Adv. Synth. Catal. 2006, 348, 1125-1148.

[22] S. Merino, L. Brauge, A. M. Caminade, J. P. Majoral, D. Taton, Y Gnanou, Chem.-Eur. J. 2001, 7, 3095-3105

[23] M. Keller, M. lanchuk, S. Ladeira, M. Taillefer, A. M. Caminade, J. P. Majoral, A. Ouali, Eur. J. Org. Chem. 2012, 1056-1062.

[24] P. Z. Chen, L. Y. Niu, Y. Z. Chen, Q. Z. Yang, Coord. Chem. Rev. 2017, 350, 196-216.

[25] C. Rouxel, O. Mongin, A. Hameau, A. Ouali, M. Blanchard-Desce, J. P Majoral, A. M. Caminade, Can. J. Chem. 2017, 95, 948-953. 
[26] H. N. Kim, M. H. Lee, H. J. Kim, J. S. Kim, J. Yoon, Chem. Soc. Rev. 2008, 37, 1465-1472.

[27] Y. Q. Wei, R. Laurent, J. P. Majoral, A. M. Caminade, Arkivoc 2010 , 318-327.

[28] A. Hameau, S. Fuchs, R. Laurent, J. P. Majoral, A. M. Caminade, Beilstein J. Org. Chem. 2011, 7, 1577-1583.

[29] A. M. Caminade, R. Laurent, B. Delavaux-Nicot, J. P. Majoral, New J. Chem. 2012, 36, 217-226.

[30] S. Fuchs, A. Pla-Quintana, S. Mazeres, A. M. Caminade, J. P. Majoral, Org. Lett. 2008, 10, 4751-4754.

[31] R. C. H. Wong, P. C. Lo, D. K. P. Ng, Coord. Chem. Rev. 2019, 379, 30-46.

[32] J. Leclaire, R. Dagiral, S. Fery-Forgues, Y. Coppel, B. Donnadieu, A. M. Caminade, J. P. Majoral, J. Am. Chem. Soc. 2005, 127, 15762-15770.

[33] J. Leclaire, R. Dagiral, A. Pla-Quintana, A. M. Caminade, J. P. Majoral, Eur. J. Inorg. Chem. 2007, 2890-2896.

[34] J. Leclaire, Y. Coppel, A. M. Caminade, J. P. Majoral, J. Am. Chem. Soc. 2004, 126, 2304-2305.

[35] M. Slany, M. Bardaji, M. J. Casanove, A. M. Caminade, J. P. Majoral, B. Chaudret, J. Am. Chem. Soc. 1995, 117, 9764-9765.

[36] M. Maszewska, J. Leclaire, M. Cieslak, B. Nawrot, A. Okruszek, A. M. Caminade, J. P. Majoral, Oligonucleotides 2003, 13, 193-205

[37] H. C. Yeh, W. C. Wu, C. T. Chen, Chem. Commun. 2003, 404-405.

[38] G. Franc, S. Mazeres, C. O. Turrin, L. Vendier, C. Duhayon, A. M. Caminade, J. P. Majoral, J. Org. Chem. 2007, 72, 8707-8715.

[39] J. Kazmierczak-Baranska, A. Pietkiewicz, M. Janicka, Y. Q. Wei, C. O. Turrin, J. P. Majoral, B. Nawrot, A. M. Caminade, Nucleosides Nucleotides \& Nucleic Acids 2010, 29, 155-167.

[40] M. Poupot, L. Griffe, P. Marchand, A. Maraval, O. Rolland, L. Martinet, F. E. L'Faqihi-Olive, C. O. Turrin, A. M. Caminade, J. J. Fournie, J. P Majoral, R. Poupot, FASEB J. 2006, 20, 2339-2351.

[41] A. M. Caminade, S. Fruchon, C. O. Turrin, M. Poupot, A. Ouali, A. Maraval, M. Garzoni, M. Maly, V. Furer, V. Kovalenko, J. P. Majoral, G. M. Pavan, R. Poupot, Nature Communications 2015, 6, 7722.

[42] M. Hayder, M. Poupot, M. Baron, D. Nigon, C. O. Turrin, A. M. Caminade, J. P. Majoral, R. A. Eisenberg, J. J. Fournie, A. Cantagrel, R. Poupot, J. L. Davignon, Sci. Transl. Med. 2011, 3, 11.

[43] M. Hayder, M. Varilh, C. O. Turrin, A. Saoudi, A. M. Caminade, R. Poupot, R. S. Liblau, Biomacromolecules 2015, 16, 3425-3433.

[44] L. Griffe, M. Poupot, P. Marchand, A. Maraval, C. O. Turrin, O. Rolland, P. Metivier, G. Bacquet, J. J. Fournie, A. M. Caminade, R. Poupot, J. P. Majoral, Angew. Chem. Int. Ed. 2007, 46, 2523-2526.

[45] M. Poupot, C. O. Turrin, A. M. Caminade, J. J. Fournie, M. Attal, R. Poupot, S. Fruchon, Nanomedicine-Nanotechnology Biology and Medicine 2016, 12, 2321-2330.

[46] E. Martinez-Ferrero, G. Franc, S. Mazeres, C. O. Turrin, U. Boissiere, A. M. Caminade, J. P. Majoral, C. Sanchez, Chem.-Eur. J. 2008, 14 7658-7669.

[47] W. L. Goh, M. Y. Lee, T. L. Joseph, S. T. Quah, C. J. Brown, C. Verma S. Brenner, F. J. Ghadessy, Y. N. Teo, J. Am. Chem. Soc. 2014, 136, 6159-6162.
[48] O. Rolland, L. Griffe, M. Poupot, A. Maraval, A. Ouali, Y. Coppel, J. J. Fournie, G. Bacquet, C. O. Turrin, A. M. Caminade, J. P. Majoral, R. Poupot, Chem.-Eur. J. 2008, 14, 4836-4850.

[49] D. Portevin, M. Poupot, O. Rolland, C. O. Turrin, J. J. Fournie, J. P Majoral, A. M. Caminade, R. Poupot, J. Transl. Med. 2009, 7, 13.

[50] M. Hayder, M. Garzoni, D. Bochicchio, A.-M. Caminade, F. Couderc, V Ong-Meang, J.-L. Davignon, C.-O. Turrin, G. M. Pavan, R. Poupot Biomacromolecules 2018, 19, 712-720.

[51] J. Ledall, S. Fruchon, M. Garzoni, G. M. Pavan, A. M. Caminade, C. O. Turrin, M. Blanzat, R. Poupot, Nanoscale 2015, 7, 17672-17684.

[52] F. lelasi, J. Ledall, A. P. Anes, S. Fruchon, A. M. Caminade, R. Poupot, C. O. Turrin, M. Blanzat, Phys. Chem. Chem. Phys. 2016, 18, 21871 21880.

[53] E. Blattes, A. Vercellone, H. Eutamene, C. O. Turrin, V. Theodorou, J. P. Majoral, A. M. Caminade, J. Prandi, J. Nigou, G. Puzo, Proc. Natl. Acad. Sci. U. S. A. 2013, 110, 8795-8800.

[54] C. Loup, M. A. Zanta, A. M. Caminade, J. P. Majoral, B. Meunier, Chem.-Eur. J. 1999, 5, 3644-3650.

[55] A. Shakhbazau, M. Mishra, T. H. Chu, C. Brideau, K. Cummins, S Tsutsui, D. Shcharbin, J. P. Majoral, S. Mignani, M. Blanchard-Desce, M. Bryszewska, V. W. Yong, P. K. Stys, J. van Minnen, Macromol. Biosci. 2015, 15, 1523-1534.

[56] N. El Brahmi, S. El Kazzouli, S. M. Mignani, E. Essassi, G. Aubert, R. Laurent, A. M. Caminade, M. M. Bousmina, T. Cresteil, J. P. Majoral, Mol. Pharm. 2013, 10, 1459-1464.

[57] S. Mignani, N. El Brahmi, L. Eloy, J. Poupon, V. Nicolas, A. Steinmetz S. El Kazzouli, M. M. Bousmina, M. Blanchard-Desce, A. M. Caminade J. P. Majoral, T. Cresteil, Eur. J. Med. Chem. 2017, 132, 142-156.

[58] S. M. Mignani, N. El Brahmi, S. El Kazzouli, R. Laurent, S. Ladeira, A. M. Caminade, E. Pedziwiatr-Werbicka, E. M. Szewczyk, M. Bryszewska, M. M. Bousmina, T. Cresteil, J.-P. Majoral, Mol. Pharm. 2017, 14, $4087-$ 4097

[59] a) O. Mongin, T. R. Krishna, M. H. V. Werts, A. M. Caminade, J. P. Majoral, M. Blanchard-Desce, Chem.Commun. 2006, 915-917; b) 0 Mongin, A. Pla-Quintana, F. Terenziani, D. Drouin, C. Le Droumaguet, A. M. Caminade, J. P. Majoral, M. Blanchard-Desce, New J. Chem. 2007, 31, 1354-1367; c) F. Terenziani, V. Parthasarathy, A. PlaQuintana, T. Maishal, A. M. Caminade, J. P. Majoral, M. Blanchard Desce, Angew. Chem. Int. Ed. 2009, 48, 8691-8694; d) C. Rouxel, M. Charlot, O. Mongin, T. R. Krishna, A. M. Caminade, J. P. Majoral, M. Blanchard-Desce, Chem.-Eur. J. 2012, 18, 16450-16462.

[60] T. R. Krishna, M. Parent, M. H. V. Werts, L. Moreaux, S. Gmouh, S Charpak, A. M. Caminade, J. P. Majoral, M. Blanchard-Desce, Angew. Chem. Int. Ed. 2006, 45, 4645-4648.

[61] A. Sourdon, M. Gary-Bobo, M. Maynadier, M. Garcia, J. P. Majoral, A M. Caminade, O. Mongin, M. Blanchard-Desce, Chem.-Eur. J. 2019, 25, 3637-3649. 


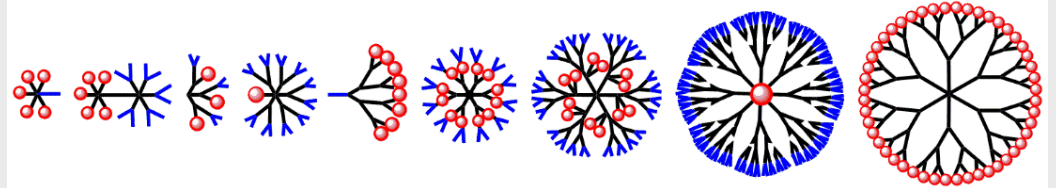

This minireview displays different types of fluorescent phosphorus dendrimers. The fluorophores are represented as red bowls, the other functions are in blue in this graphical abstract. Diverse types of fluorophores have been used such as pyrene, naphthol, anthracene, dansyl, diketone, phthalocyanine, maleimide, julolidine, rhodamine, fluorescein or fluorene derivatives. These compounds have been used in the fields of catalysis, nanomaterials, OLEDs, sensors and biology/nanomedicine, as transfection, anti-inflammatory, or anti-cancer agents.
Jieru Qiu, Aurélien Hameau, Xiangyang Shi, Serge Mignani, Jean-Pierre Majoral and Anne-Marie Caminade*

Page No. - Page No.

Fluorescent Phosphorus Dendrimers: Towards Material and Biological Applications 